Profesor de la Universidad Johannes Güttemberg de la Universidad de Maguncia (Mainz), donde ejerce como docente del Seminario de Filología Románica, es un profundo estudioso de la lengua guaraní. Sus actividades en el Seminario de Filología Románica se centran en la enseñanza del español, de las literaturas hispánicas y la cultura latinoamericana. Se interesó por el Paraguay y su cultura bilingüe gracias a sus estudios de las obras de Augusto Roa Bastos. Es uno de los mayores conocedores de la literatura en guaraní, además del estudioso más notable de esta lengua en Europa, hecho que revela la realización de varios diccionarios. Se encarga de una de las páginas web más nutridas sobre civilización guaraní y literatura paraguaya en general. Es autor, además, de numerosos trabajos sobre estos temas.

\title{
LITERATURA PARAGUAYA EN GUARANÍ
}

WOLF LUSTIG (MAGUNCIA)

El Paraguay es el único país latinoamericano donde la lengua de los «vencidos» ha mantenido su vigor hasta el siglo XXI. Es más: la Constitución de 1992 establece definitivamente en su Artículo 140: «El Paraguay es un país pluricultural y bilingüe. Son idiomas oficiales el castellano y el guaraní.» Pero sería un error pensar que la situación lingüística se deba a la importancia demográfica de la población indígena «mestiza» en esta céntrica república sudamericana: las comunidades indígenas guaraní-hablantes en su totalidad ya no corresponden a más del 1 \% de la población, pero casi la totalidad de los paraguayos conoce el ava ñe'ẽ («la lengua del hombre») y lo emplea parcialmente en la comunicación oral diaria (Steckbauer 1999, 386 ss.).

De ahí que, hablando de literatura guaraní y de literatura paraguaya, se imponga distinguir entre literatura (indígena) guaraní y literatura paraguaya en guarani - aun a sabiendas de que la segunda comparte y hereda temas y problemas de la primera y que, en ambos casos, la aplicación del término literatura es algo problemática. Si bien hubo varios intentos de «reducir a escritura» el guaraní ( $\mathrm{Me}$ lià 1995, 90) desde el tiempo de los jesuitas, de hecho mantuvo su carácter básicamente oral (además de marginado) hasta las postrimerías del siglo XX. Si tomamos en serio el concepto de literatura paraguaya en guaraní como «arte de la palabra escrita por la cual el pueblo paraguayo expresa su cultura en su propia lengua», no sería exagerado decir que las últimas tres décadas son el período de emergencia, de gestación y (re)nacimiento de una nueva literatura sobre raíces antiguas.
Ya es un tópico hablar de la literatura paraguaya como terra incognita y del texto ausente como referencia simbólica a la falta de tradición literaria (Sánchez 1968; Roa Bastos 1984). Lo que es válido para la literatura en castellano lo es mucho más para su «otra vertiente» en guaraní, considerada como especie de subtexto de lo escrito en castellano. Pero también hay que tener en cuenta que lo ausente sólo ha sido el texto escrito y que la palabra viva guaraní-paraguaya ha pasado sencillamente desapercibida porque no había «letrados» que supieran escucharla. La salida del aislamiento, el acceso a la escritura le estaban vedados por obstáculos de variada índole, parcialmente exteriores y ajenos al fenómeno literario.

Antes de proceder a una muy reducida selección de autores y obras representativos de los dos grandes períodos por los que ha pasado el fenómeno que nos interesa, intentaremos echar luz sobre el contexto cultural, sociolingüístico e incluso político del que surge la voz guaraní en la literatura paraguaya.

\section{EL ARTE DE LA PALABRA INDÍGE- NA GUARANÍ}

Un rasgo intrínseco del arte de la palabra entre las etnias nativas guaraníes ha sido y sigue siendo la oralidad - ciertamente no sentida como limitación sino como algo susceptible de enriquecerse con formas de expresión no verbales como la música, la danza y los gestos. Lo que de este acervo ha pasado a las páginas de hermosas antologías (López Austin 1965; Bareiro Saguier 1980), originariamente se expresa en las formas rituales del 
canto sagrado y puede constituir - para quien sabe abrirse a su encanto - una entrada a un universo muy alejado de la cultura libresca de Occidente. Aunque en realidad es «de otro mundo», la oratura guaraní ha fascinado a los poetas paraguayos modernos y últimamente se ha convertido en una fuente de inspiración importante para la literatura paraguaya, sea que esta se exprese en castellano o en guaraní. Podemos citar como ejemplo el ya clásico himno sagrado mbya guaraní Ayvu rapyta, en el que toma forma el carácter sagrado del lenguaje y la palabra (Cadogan 1992, 32s.):

\section{Ñamandu Ru Ete tenondegua}

$[E]$ verdadero Padre Namandú, el primero, oyvára peteĩgui,

[de una pequeña porción de su propia divinidad, oyvárapy mba’ekuaágui,

[de la sabiduría contenida en su propia divinidad, okuaararávyma

[y en virtud de su sabiduría creadora tataendy, tatachína ogueromoñemoña.

[hizo que se engendrasen llamas y tenue neblina.

\section{Oãmyvyma,}

[Habiéndose erguido, oyvárapy mba’ekuaágui,

[de la sabiduría contenida en su propia divinidad, okuaararávyma

[y en virtud de su sabiduría creadora ayvu rapytarã i oikuaa ojeupe.

[concibió el origen del lenguaje humano.

Oyvárapy mba'ekuaágui,

[de la sabiduría contenida en su propia divinidad, okuaararávyma,

[y en virtud de su sabiduría creadora, ayvu rapyta oguerojera

[creó nuestro Padre el fundamento del lenguaje humano ogueroyvára Ñande Ru. [...]

[e hizo que formara parte de su propia divinidad [...].

\section{LA TRADICIÓN ORAL GUARANÍ PARAGUAYA: UN LARGO DESTIE- RRO DE LA REPÚBLICA DE LAS LETRAS}

La tradición popular con la que entronca la actual literatura paraguaya en guaraní es también marcadamente oral, aun cuando se haya alejado o hasta se haya distanciado de su remoto substrato indígena. La imaginación y la sabiduría colectivas se han volcado durante siglos sobre todo en los siguientes géneros (cf. González Torres 1992):

- narrativos: el káso y el mombe'u gua'u (cuento 'ficticio'): breves historias verdaderas o inventadas, a menudo satírico-humorísticas y protagonizadas por personajes y figuras típicas como el mono ka'i, el pychãi (pobre pícaro que tiene los pies llenos de niguas) - Perurima, lejano descendiente de Pedro de Urdemalas, así como las leyendas sobre seres fabulosos que en parte provienen de la mitología indígena, como el duende del bosque jasy jatere ${ }^{1}$;

- líricos: las coplas de las antiguas canciones populares (a veces más narrativas que poéticas), las letras de canciones (purabéi) cantadas al ritmo de la polca paraguaya o la nostálgica guarania; los rítmicos versos de las adivinanzas populares e infantiles; los cantos relacionados con la Navidad y otras festividades religiosas;

- dramáticos: el teatro popular e improvisado en el que, según la categoría social de los personajes, se puede mezclar, de forma espontánea y natural el discurso en guaraní con el castellano;

- pragmáticos: el rico caudal de los ñe'ẽnga, proverbios que en un tono serio-jocoso reflejan la sabiduría del campesino paraguayo, p. ej.: Mboriabu memby reikuaa baguã, ijyva puku ba iñe'êkuad mantearã («para que conozcas al hijo de la mujer pobre: siempre tiene los brazos largos [de tanto trabajar] y sabe hablar bien») (Aguilera 1996, 97).

Una consecuencia de la diglosia que durante siglos marginó al guaraní y sus hablantes fue que esta cultura sólo en muy contadas excepciones fuera considerada digna de la escritura: el idioma de las letras, por principio, tenía que ser el castellano. Apenas en determinadas constelaciones históricas - especialmente en los períodos de guerra, marcados por su extremo nacionalismo y por la necesidad de construirse una identidad diferenciadora frente a las naciones vecinas - se estimuló la actividad literaria en el idioma nativo. En muchas ocasiones, sin
1 traducción interlinear se encuentra en Lusfig, 1995. Sobre el folklore «literario» del Paraguay véase Cardozo Ocampo 1991 y González Torres 1992. 


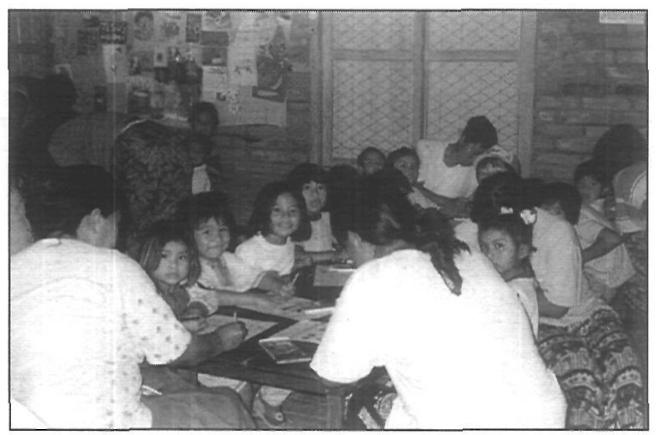

Niños indígenas en la escuela. (Foto: Mar Langa). embargo, no llegó a superarse el desprecio por la auténtica cultura del pueblo y se recurrió a modelos copiados de los «centros» culturales y a un lenguaje artificial y elaborado. Así no han faltado ni los versos encomiásticos que ensalzan los progresos de la civilización técnica en forma de hexámetros ni los inten2 En el ámbito de la política lingüistica - tal como exitosamente se aplica en Caraluña- la normalización de una lengua inicialmente marginada significa que ésta vuelva a emplearse «normalmente» en todos los ámbitos y todas las formas de comunicación.

\section{3}

El empleo «normalizado» en la enseñanza y el uso en los libros de texto puede llevar a la aceptación de un término como ñe'ẽporãhaipyre, que también corresponde al título del hasta ahora único manual didáctico de literatura paraguaya en guaraní (Acosta Alcaraz 1995). Sin embargo existe la propuesta de otro término: ñe'ẽporãporavopyre que hace referencia más bien a "las bellas palabras seleccionadas» y abarca tanto lo escrito como lo oral. tos de traducir el Quijote al guaraní.

Hasta se podría formular la hipótesis de una «diglosia de segundo grado» que escinde en dos el dominio de la cultura paraguaya de expresión guaraní y que más que nunca constituye un problema para su «normalización» ${ }^{2}$ en el ámbito literario. Es decir, los «profesionales» de la cultura, o por lo menos un poderoso sector entre ellos hablan y sobre todo escriben y prescriben un guaraní que no es el del pueblo, aferrándose a una absurda "pureza» de la lengua. Según los defensores del guaraniete (el «verdadero» guaraní), al escribir en la lengua autóctona hay que reducir al mínimo el uso de hispanismos - requisito muy difícil de cumplir si se considera que, debido a las restricciones impuestas al uso del idioma, el léxico cubre principalmente las necesidades de una sociedad campesina de principios del siglo XIX. Es verdad que la estructura polisintética del guaraní facilita la formación de neologismos: así se ha acuñado, p. ej., el término ñe'êporãbaipyre para «literatura» ${ }^{3}$. Pero el que no está iniciado en la terminología especializada entiende a lo sumo «escritura de hermosas palabras» y para él la lectura de un texto plagado de tales creaciones puede convertirse en un frustrante juego de adivinanzas. No se pueden cerrar los ojos ante el hecho de que la realidad lingüística del Paraguay está caracterizada por la profunda compenetración léxica y sintáctica del guaraní con el español paraguayo. El discurso jopara, cuya estructura es esencialmente guaraní pero que integra un alto porcentaje de vocabulario español (cf. Lustig 1996), sale - muy a pesar de algunos maestros - de la boca de todos.

\section{PRIMER CICLO: PATRIOTISMO Y FOLKLORIZACIÓN}

Si ahora queremos desenterrar los gérmenes de lo que con derecho se puede llamar «li- teratura en guaraní» tenemos que volver a la segunda mitad del siglo XIX. Su «padrino» es en cierto sentido el Cacique Lambaré, la primera revista exclusivamente en guaraní que apareció como órgano de propaganda en 1867, durante la Guerra de la Triple Alianza contra el Brasil, la Argentina y el Uruguay. En sus páginas (y en las de otras revistas de guerra de la misma época) encontramos artículos programáticos que reivindican la creación de una literatura nacional y patriótica en la lengua nativa (Lustig 2002). Numerosas contribuciones, que habría que adscribir a los géneros tradicionalmente orales de la canción y el káso, ilustran la posibilidad de «escribir bien» en guaraní, incluso según reglas ortográficas relativamente coherentes, concebidas especialmente para las revistas. Las muestras de esta nueva literatura adolecen ciertamente de una alta carga ideológica y un tono sumamente panfletario.

Sin embargo, esta instrumentalización ideológica será la característica predominante de la literatura en guaraní prácticamente hasta mediados del siglo XX. Como paradigmático representante de la «generación nacionalista indigenista» (cf. Bareiro Saguier 1978) se podría mencionar al «poeta de la raza» Narciso R. Colmán. Entre otras obras más bien de inspiración folklórica publicó, en 1929, bajo el seudónimo de Rosicrán, Ñande Ypykuéra, un intento de recrear románticamente el mito de los orígenes guaraní-paraguayos (cf. Melià 1992, 208). Ya el subtítulo de su obra es programático: Poema etnogenético y mitológico. Protobistoria de la Raza guarani, seguida de un estudio etimológico de los mitos, nombres y voces empleadas.

La literatura «épica» en guaraní - en el contexto paraguayo lo épico tiene una conexión estrecha con lo marcial y lo patriótico- encuentra su culminación en las creaciones sumamente exitosas del «Tirteo verdeolivo» Emiliano R. Fernández. Sus canciones de la Guerra del Chaco (1936-39), que en su momento levantaron el ánimo de los combatientes, circulan hasta hoy en numerosas antologías, además de los discos y casetes que inmortalizan musicalmente al vate popular (Lustig 1997; Romero 1996).

La literatura de esta primera fase se articula bajo el signo de lo folklórico y lo patriótico, y muy a menudo se pone deliberadamente al servicio del régimen. Como última muestra de esta vena citamos una estrofa de la 
canción Ta ipoty ñande reta (Taipoty ñane retã / «Que florezca nuestra nación») que el folklorista, poeta y compositor Mauricio Cardozo Ocampo dedica, en una recopilación de sus obras, al dictador Alfredo Stroessner (Cardozo Ocampo 1980, 119)4:

Nde che retä Paraguái

[A ti mi patria paraguaya,

ndévena ta purajhei

[a ti quiero cantar,

jhi'äitégui amombe'ú

[porque me da gusto voy a contar

mba'eichaitépa ne porä.

[cuán hermosa eres.

Ndaipórico ndeicha guá

[No hay otra como tú

re mimbi re jhesapé,

[que brillas y alumbras,

jhetaité mba'é porä

[tantas cosas lindas

re recóva nde pypé. [...]

[que tienes dentro de ti. [...]

Peina General Stroessner

[He aquí el General Stroessner

oisambyjhy ñande retä

[que conduce nuestra patria,

ichupé ñaipytyvóne

[a él le vamos a ayudar,

yaipotáramo opu'ä.

[si queremos que crezca (la nación).

\section{CAMBIO DE CLIMA Y NUEVA IN- FRAESTRUCTURA}

A partir de la década de los 80 el panorama de las letras en guaraní experimenta una reestructuración profunda. Una de las razones reside, seguramente, en que la pobreza, la injusticia y la opresión sufridas por una gran parte del pueblo paraguayo bajo el régimen de Stroessner, cada vez más insoportable, buscan y encuentran su expresión literaria genuina en la lengua de los pobres, que es el guaraní. $\mathrm{Pa}$ rece sintomático al respecto un breve texto literario en guaraní que Roa Bastos emplea como leitmotiv del Capítulo IV de Hijo de hombres: el canto del mensú, explotado trabajador de los yerbales.

Anive angána, che compañero,

[iAy, mi compañero! ¡No sigas

ore korazõ reikytĩ asy ${ }^{6}$

[rompiendo cruelmente nuestro corazón!
Para esa generación de escritores e intelectuales, recuperar la lengua empobrecida y marginada es en sí un acto de protesta y compromiso y no implica necesariamente una temática abiertamente política (que además había que evitar en el contexto de la

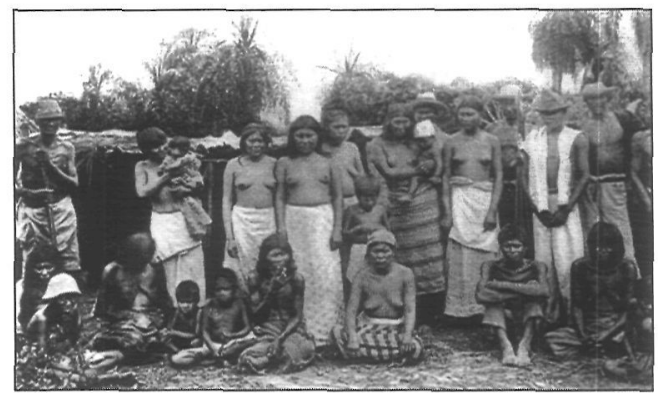

Encomiendas indígenas. (Foto: archivo de Jorge Rubbiani). persecución y la censura).

Entre las revistas que surgen en ese período, puestas al servicio del fomento y la divulgación de la literatura, destaca la revista bilingüe de cultura Nemitÿ («siembra»), que acoge contribuciones literarias en guaraní de todos los géneros, además de artículos de crítica literaria y de lingüística. Desde 1977 se han publicado más de cuarenta números.

Lo que después de la caída de la dictadura favorece sobremanera la eclosión de la literatura en guaraní es - más que la mera oficialización del idioma en la Constitución de 1992- la Reforma Educativa, que vuelve obligatoria la enseñanza de la lengua y la literatura guaraní en la Educación Escolar Básica e implementa por primera vez, desde el tiempo de los jesuitas, las prácticas de lectoescritura ${ }^{7}$. En los nuevos libros de texto ${ }^{8}$ se valoran y estudian obras y autores e incluso se estimula la creatividad literaria de los alumnos.

Esta intromisión estatal ha estimulado el mercado del libro en guaraní. Como deducimos - entre otras fuentes - del catálogo de Guarani Raity, la hasta ahora única librería especializada para libros en guaraní, desde 1981 han aparecido más de 90 títulos en los géneros poesía, narrativa, teatro y antologías. El gráfico demuestra que, una vez sueltas «las ataduras de la lengua» con la democratización de 1989, la producción editorial conoce un aumento considerable, especialmente a partir la implementación definitiva de la educación bilingüe en 1994, y que el género literario más cultivado es la poesía.
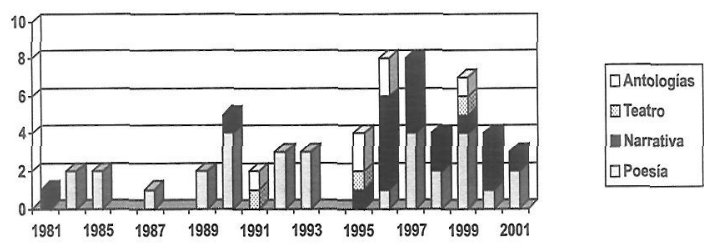

La reproducción del texto viene acompañada de una copia de la carta que dirige el autor al entonces Presidente dedicándole sus versos «como un pequeño homenaje a su monumental obra en bien de nuestra patria». (Respetamos las inconsecuencias de la grafía y la fonosintaxis.)

5

Otro texto de origen guaraní, que sirve de epígrafe, es tomado de un himno sagrado de los mbya: «...He de hacer que la voz vuelva a fluir por los huesos... / $Y$ haré que vuelva a encarnarse el habla... / Después que se pierda este tiempo y un nuevo tiempo amanezca...».

6

Roa Bastos 1990: 108, 130, 131. Grafía actualizada. Se trata de un fragmento de la guarania Ka'aly (Yerbal) de Rigoberto Fontao Meza, que debe datar de los años 30 .

7

Ya la Constitución de 1967 había reconocido que de hecho el guaraní era la lengua nacional (no oficial) y preveía la enseñanza en guaraní con el fin de integrar a los niños monolingües en la sociedad hispanohablante.

8

Lengua y literatura 1999-2001. Según el catálogo de Guarani Raily han aparecido desde 1994 por lo menos 72 tírulos de este género además de 10 publicaciones en la categoría Lectura en guaraní.

9

Para la nómina de los autores y títulos remitimos a hitp://wuww.unimainz.de/ lustig/guarani/libros/tabla.htm.

Literatura paraguaya en guaraní WOLF LUSTIG 
Accesible por hitp://www.guarani.de

11

hitp://mww.cervantesvirtual.com /portal/paraguay/ - Aquí se puede consultar Karai Rrei oha'ãramo guare tuka'ẽ kañy ("De cuando Karai Rey jugó a las escondidas»), de Juan Bautista Rivarola Matto, en versión bilingüe.

12

Una escena en versión bilingüe es accesible en hitp://www.unimainz.de/ lustig/guarani/sandia.htm.

13

El texto de Rubén Rolandi conserva ciertas marcas ritualizadas del discurso narrativo oral, p. ej. hace terminar cada uno de sus kásos con la fórmula ha upépe opa ("y ahí se acaba»).

14

Cf. Lustig 1996, donde se comentan algunos aspectos lingüistico-literarios de este texto. Una nota biográfica sobre la autora, así como un extracto de Ramona Quebranto, está disponible en el mencionado sitio de la Biblioteca Virtual Cervantes (hittp://cervantesvirtual.com

15

Sobre la lírica moderna en guaraní compárese Lustig 1997 en la antología de Méndez-Faith, la cual ofrece una visión de conjunto de la lírica en guaraní desde finales del siglo XIX.
La expansión de Internet como medio de publicación y divulgación constituye otro factor que influye positivamente en la revitalización de muchas lenguas y literaturas minorizadas. Citemos como ejemplo el sitio Guarani Nanduti Rogue ${ }^{10}$, que desde 1995 se dedica a la cultura paraguaya de expresión guaraní y ofrece una plataforma para la publicación de textos clásicos y actuales. Recientemente la Biblioteca Virtual Miguel de Cervantes inauguró un portal de literatura paraguaya en el cual aparecen textos íntegros de narrativa en guaraní11.

\section{SEGUNDO CICLO: LA EMANCIPA- CIÓN DE LA PALABRA EN GUA- RANÍ}

No existe todavía ninguna historia de la literatura en guaraní, pero se cuenta con algunos trabajos que dan una idea bastante completa del quehacer literario guaraní-paraguayo (Pla 1973, Melià 1992, Acosta 1995, Méndez Faith 1997). Por lo tanto nos limitaremos a mencionar para cada género dos o tres obras $y$ autores que consideramos representativos de las tendencias actuales.

Empezamos con el teatro que se presenta como un género-puente entre la vieja y la nueva literatura en guaraní porque desde siempre ha mantenido el contacto con la auténtica realidad lingüística y social del pueblo, y no ha sido alterado por el pasaje a la escritura, que sigue siendo el mero soporte de lo oral. En no pocas ocasiones las piezas llegaron a la imprenta con unos 50 años de retraso, como en el caso de Sandía yvyguy («Sandía enterrada», 1933/1981) ${ }^{12}$ y Karu pokã («Los mal comidos», 1941/1980) de Julio Correa (18901954), uno de los pioneros de la nueva literatura en guaraní, tanto en el teatro como en la poesía (cf. Romero 1995). La Guerra del Chaco, ambiente de las piezas de Correa, persiste como tema de obras dramáticas más recientes como Anivéna karaikuéra ("iBasta, señores!», 1995) de Demetrio Ortiz. Como el teatro popular se enriquece considerablemente con la realización escénica e integra siempre una gran dosis de improvisación, pertenece más a lo oral que a lo escrito. A pesar de ello tiene una función cada vez más importante para la literatura en guaraní, ya que muchos textos originariamente narrativos llegaron al gran público por vía de una adaptación teatral, así como muchos textos líricos se popularizaron a través de canciones.

Posteriormente llevado al palco fue también Kalaito Pombero (1981) de Tadeo Zarratea (1947). Esta obra, que temática y estructuralmente se insiere en la tradición picaresca-costumbrista, destaca por ser la primera novela escrita originariamente en guaraní. Una práctica que obedece a la falta de costumbre de leer en guaraní es que los textos - Kalaíto Pombero así como la mayoría de los volúmenes de poesía - se editan en versión bilingüe. Paralelamente a lo que podemos llamar la "narrativa culta» se sigue cultivando el káso ñemombe'u («el contar 'casos»), que en sus versiones escritas, algunas veces destinadas primordialmente al uso didáctico, no necesariamente pierden su encanto. Como ejemplo de este género se puede mencionar la colección Kásos. Abendu abai (1989) de Rubén Rolandi, donde se dan cita los fantásticos seres y las creencias que pueblan la imaginación campesina, como Luisõ, Pombéro, karai Rréi y la esperanza de encontrar pláta yoyguy, los legendarios tesoros enterrados durante la Guerra Grande ${ }^{13}$.

En la mayoría de los textos literarios en guaraní se nota cierto afán de «defensa e ilustración de la lengua». Se evita el contagio del jopara, «habla idiota de la senilidad colectiva, el ñe'ê tavy del débil mental», según el juicio de Roa Bastos (1993, 280). Precisamente por ello merece mención Margot Ayala de Michelagnoli (1935) con su novela corta (llevada exitosamente al teatro por Mario Halley Mora) Ramona Quebranto (1989). Cuenta - o más bien representa en diálogos sumamente naturales, en la típica mezcla caótica de guaraní y español paraguayo - los «quebrantos» de una joven mujer de origen campesino que intenta sobrevivir de alguna forma en una barriada de Asunción ${ }^{14}$.

Es en el campo de la lírica donde son más notables las innovaciones que caracterizan la escritura en guaraní del último cuarto del siglo $\mathrm{XX}^{15}$. La poesía se emancipa y se «descolonializa»: supera la retórica heredada del romanticismo y abandona los metros clásicos de la tradición hispánica o grecolatina que forzaban el verbo guaraní en un lecho de Procusto. No es exagerado decir que la lírica moderna en guaraní libera la lengua de su cárcel, rompiendo sus ataduras, como lo proclaman lite- 
ralmente los versos de Félix de Guarania (1924) en el poemario Tojery kuaraby ("Que vuelva el sol») de 1989:

$\begin{array}{ll}\begin{array}{l}\text { Añandu } \\ \text { che pirĩ }\end{array} & \text { Siento } \\ \text { hoy'sã } & \text { escalofríos } \\ \text { che aguije. } & \text { se enfría } \\ \text { Kirirĩ̃ } & \text { mi alma. } \\ \text { kyhyje, } & \text { Silencio, } \\ \text { tekove } & \text { temor, } \\ \text { oñapytĩ. } & \text { vida } \\ \text { ¡Mba'épo } & \text { atada. } \\ \text { ojehu } & \text { ¡Qué } \\ \text { che retã } & \text { pasa! } \\ \text { i'ñe'ẽngu! } & \text { ¡Mi país } \\ & \text { está mudo! } \\ \text { ¡Anive } & \text { Suelten } \\ \text { peipykua ñe’ẽ! } & \text { las ataduras de la lengua! } \\ \text { Peheja } & \text { Dejen que } \\ \text { toveve, } & \text { vuele, } \\ \text { tohasa, } & \text { pase, } \\ \text { toheka } & \text { busque } \\ \text { tape, } & \text { camino, } \\ \text { tojoka } & \text { rompa } \\ \text { ko'ẽ... } & \text { el amanecer... }\end{array}$

Estéticamente, la originalidad de la nueva poesía consiste en que pone en evidencia las insólitas calidades rítmicas y musicales del guaraní. Ramón R. Silva (1954) da un paso más en esta dirección. Su especialidad es el estilo tangara, que ha dado el título a un poemario publicado en 1985 . Se inspira en una danza de los Mbya, en la cual la magia del ritmo acercaba al hombre de las fuerzas primigenias. Pero no se trata de una incursión anacrónica en lo indigenista (cf. Lewis 1991) o de una indagación etnográfica. En el poema Paraguái ñe $e^{16}$, por ejemplo, la fuerza «mágica» de la palabra conmoverá a cualquier paraguayo de habla guaraní, y no dejará de fascinar a los lectores o, mejor, «oyentes» que no participen de aquel trasfondo cultural.

Como tercera y última figura en el concierto de nuevas voces en guaraní mencionaremos a Susy Delgado (1942), que con $\mathrm{Ta}$ taypype («Junto al fuego», 1992), llegó a finalista en el concurso del Premio Casa de las Américas de 1991. El tataypy, lugar donde se enciende y guarda el fuego en la casa campesina, se constituye en símbolo del mundo guaraní (Delgado 1992, 48ss.):

Toupáke

QQue vengan todos

chaguélo ñeẽme

[los que han resucitado

oikove jeýva.

[en la voz del abuelo.

Toguerúke hikuái

[Que traigan

hembiasakue,

[sus historias

tomyasãi tataypýpe,

[y las desparramen junto al fuego

tañanemondýi,

[para que nos asusten,

tañanemombáy,

[nos desperecen

toñembosarái ñanendive.

[y jueguen con nosotros.

Toúke hikuái,

[Que vengan,

toguapy, topyta,

[se sienten y se queden

ha mitã toipe'áke hesa,

[y que abran sus ojos los niños,

taipirĩ,

[tengan escalofrios

topuka.

[y rían.

Taiko'êke mitã akã ruguápe,

IY que amanezca en el fondo de su memoria,

ñe'ẽ.

[la palabra.

En la constitución formal del texto son evidentes las aliteraciones y los paralelismos que realzan la sonoridad y el ritmo de la palabra. A nivel del significado se observa cómo el tataypy ya no es sólo el lugar del fuego sino también el asentamiento de la palabra - el ayou rapyta, que fue el punto de partida de nuestro recorrido por el universo del guaraníne'ê. En torno de él se realizan la comunicación y el intercambio entre las generaciones en forma de voces y relatos. La dimensión pragmática tiene el doble cariz de invitación y plegaria: un convite dirigido a la gran familia a reunirse alrededor del fuego y escuchar la palabra, y al mismo tiempo una oración para que la palabra en guaraní no pierda su virtud salvadora entre las futuras generaciones.

Ha upépe opa.
16

Silva 1985. El texto completo con traducción se puede consultar en hitp://mww.uni-mainz.de/ /ustig/guarani/paranee.hm. 


\section{BIBLIOGRAFÍA}

ACOSTA ALCARAZ, Feliciano, Ñe'êporãbaipyre. Asunción, 1995.

AGUILERA, Domingo Adolfo, Ñe'ẽnga. Dichos populares paraguayos. Asunción, CEPAG, 1996.

BAREIRO SAGUIER, Rubén, «La generación nacionalista indigenista del Paraguay y la cultura guarani», en Actes du XLIIe Congrès International des Américanistes, Paris, 1976, págs. 549-555.

CADOGAN, León, Ayvu rapyta. Textos míticos de los Mbyá-Guarani del Guairá. Asunción, CEADUC-CEPAG, 1992.

CARDOZO OCAMPO, Mauricio, Mis bodas de oro con el Folklore paraguayo. Memorias de un Pychãi. Asunción, Ed. Cuadernos Republicanos, 1980 (11972).

CARDOZO OCAMPO, Mauricio, Mundo folklórico Paraguayo. 3 Vols. Asunción, Ed. Cuadernos Republicanos, 1992.

DELGADO, Susy, Tataypype - Junto al fuego. Asunción, Arandurã, [1992].

GONZÁlEZ TORRES, Dionisio M., Folklore del Paraguay. Asunción, 1992.

GUARANIA, Félix de, Tojevy kuaraby. Asunción, 1989.

- Lengua y literatura castellano / guaraní[3 vols. $7^{\circ}-9^{\circ}$ grado], Asunción, Santillana/Alianza, 1999-2001.

LEWIS, Tracy K., «Indígena e Indigenista en la literatura guaranítica paraguaya. ¿Un fracaso de etiquetas?», en PREUSS, Mary H. (ed.). Past, Present and Future. Selected papers on Latin American Literatures, Culver City, Labyrinthos, 1991, págs. 123-28.

LÓPEZ AUSTIN, Alfredo, La literatura de los Guaraníes. Introducción, selección y notas por León Cadogan. México, Mortiz, 1965.

LUSTIG, Wolf, «Ein Portrait des 'guaraní paraguayo», Hispanorama, 69 (1995), págs. 19-27.

LUSTIG, Wolf, «Mba'éichapa oiko la guarani», Papia, 4:2 (1996), págs. 19-43.

LUSTIG, Wolf, «Ñande reko y modernidad. Hacia una nueva poesía en guaraní», en MÉNDEZ FAITH 1997, págs. 21-48.

LUSTIG, Wolf, «Chácore purahéi-canciones de guerra. Literatura popular en guaraní e identidad nacional en el Paraguay», en POT'THAST 1999, pp. 363-379.

Literatura paraguaya en guaraní WOLF LUSTIG
LUSTIG, Wolf, «Die Auferstehung des Cacique Lambaré. Zur Konstruktion der gua- rani-paraguayischen Identität während der 'Guerra de la Triple Alianza'», en LANG, Sabine / BLASER, Jutta / LUSTIG, Wolf (eds.). 'Miradas entrecruzadas' - Diskurse interkultureller Erfabrung und deren literarische Inszenierung. Beiträge eines bispanoamerikanistischen Forschungskolloquiums zu Ehren von Dieter Janik. Frankfurt/M., Vervuert, 2002, págs. 159-185. MELIÀ, Bartomeu, La lengua guaraní del Paraguay. Historia, sociedad y literatura. Madrid, MAPFRE, 1992.

MELIÀ, Bartomeu, «Reducción literaria y alfabetización», en MELIÀ, Bartomeu. Elogio de la lengua guaraní. Contextos para una educación bilingüe en el Paraguay, Asunción: CEPAG, 1995, págs. 89-98.

MÉNDEZ FAITH, Teresa, Poesía paraguaya de ayer y de boy. Tomo II, Guarani - español. Asunción: Intercontinental, 1997.

PLA, Josefina, «La literatura paraguaya en una situación de bilingüismo», en PLA, Josefina. Obras completas. Ed. de M. A. Fernández, Asunción: RP Ediciones, 1992, III, págs. 7-35.

POT'THAST, Barbara / KOHUT, Karl / KOHLHEPP, Gerd (eds.), El espacio interior de América del Sur. geografía, bistoria, política, cultura, Frankfurt/M, Vervuert, 1999.

ROA BASTOS, Augusto, «La narrativa paraguaya en el contexto de la narrativa hispanoamericana actual», en SCHRADER, Ludwig (ed.). Augusto Roa Bastos. Actas del Coloquio Franco-Alemán (Düsseldorf, 1-3 de junio de 1982), editadas por Ludwig Schrader. Tübingen, Niemeyer, 1984, págs. 1-11.

ROA BASTOS, Augusto, Hijo de hombre. Buenos Aires, Sudamericana (2a edición), 1990.

ROA BASTOS, Augusto, "Del buen uso de los mitos», en TOVAR, Paco. Augusto Roa Bastos. Antología narrativa y poética, Barcelona, Anthropos, 1991, págs. 78-80.

ROA BASTOS, Augusto, El Fiscal. Buenos Aires, Sudamericana, 1993.

ROMERO, Roberto A., Protagonismo bistórico del idioma Guarani. Asunción, 1992.

ROMERO, Roberto A., Julio Correa. Escritor social. Asunción, Universidad Autónoma, 1995.

ROMERO, Roberto A., Emiliano R. Fernández. Mito y realidad. Asunción, 1996. 
SÁNCHEZ, Luis Alberto, Proceso y contenido de la novela hispanoamericana. Madrid, Gredos, 1968.

SILVA, Ramón R., Tangara Tangara, Asunción, Eds. Taller, 1985.
STECKBAUER, Sonja, «La situación del guaraní en el Paraguay actual», en POTTHAST 1999, págs. 381-399. 